\title{
HIF-1 $\alpha$ RNAi Combined with Asparagus Polysaccharide Exerts an Antiangiogenesis Effect on Hepatocellular Carcinoma In Vitro and In Vivo
}

\author{
Tingting Zhu $\left(\mathbb{D}\right.$, Ziwei Cheng $\left(\mathbb{D}\right.$, Xiaolin Peng $\mathbb{D}^{\mathrm{D}}$, Dongwei Xing $\mathbb{D}^{\mathrm{D}}$, \\ and Minguang Zhang $(\mathbb{D}$
}

Shanghai Municipal Hospital of Traditional Chinese Medicine, Shanghai University of Traditional Chinese Medicine, Shanghai 200071, China

Correspondence should be addressed to Dongwei Xing; xdw021@163.com and Minguang Zhang; mgzhang09@163.com

Received 23 March 2021; Revised 6 July 2021; Accepted 10 July 2021; Published 23 July 2021

Academic Editor: Francesca Mancianti

Copyright (C) 2021 Tingting Zhu et al. This is an open access article distributed under the Creative Commons Attribution License, which permits unrestricted use, distribution, and reproduction in any medium, provided the original work is properly cited.

\begin{abstract}
Background. Hepatocellular carcinoma (HCC) is the main form of primary liver cancer and is one of the most prevalent and lifethreatening malignancies globally. Hypoxia activates hypoxia-inducible factor- $1 \alpha$ (HIF-1 $\alpha$ ), which is the key factor in promoting angiogenesis in HCC. Currently, there are few studies on the effects of HIF- $1 \alpha$-targeted gene therapy combined with traditional Chinese herbal extracts. Objective. We investigated the effects of HIF-1 $\alpha$ RNA interference (RNAi) combined with asparagus polysaccharide (ASP) on HCC in vitro and in vivo. Methods. CCK-8, wound-healing, transwell, and human umbilical vein endothelial cell tube formation assays were performed to evaluate the proliferation, migration, invasion, and angiogenesis of HCC cells in vitro. In addition, western blotting, qPCR, and immunohistochemistry were performed to detect the expression of HIF-1 $\alpha$, vascular endothelial growth factor, AKT, p-AKT, ERK, p-ERK, and CD34 in HCC cells. Results. The combination of HIF-1 $\alpha$ RNAi and ASP significantly inhibited the proliferation, migration, invasion, and angiogenesis of SK-Hep1 and Hep-3B cells compared with the use of HIF-1 $\alpha$ RNAi or ASP alone. In addition, this combined treatment was shown to exert these effects by regulating the PI3K and MAPK signaling pathways. These results were observed both in vitro and in vivo. Conclusion. Our study indicates that HIF- $1 \alpha$ RNAi combined with ASP inhibits angiogenesis in HCC via the PI3K and MAPK signaling pathways. Thus, we suggest that this combination may be an effective method for the comprehensive treatment of HCC, which may provide new ideas for the treatment of other malignant tumors.
\end{abstract}

\section{Introduction}

Hepatocellular carcinoma (HCC) is a common malignancy of the digestive system. Globally, the number of new cases reaches 841,000 every year, making it the sixth most prevalent malignant tumor, and the number of deaths is 782,000 per year, ranking second among malignant tumors. China has a high incidence of HCC, and more than half of all HCC cases worldwide occur in this country [1-3]. Early-stage HCC can be treated curatively by local ablation, surgical resection, or liver transplantation, but only $40 \%$ of patients with HCC are diagnosed at an early stage $[4,5]$.

HCC is a solid tumor rich in blood vessels, and angiogenesis plays a crucial role in its occurrence, development, recurrence, and metastasis; thus, intrahepatic metastasis can occur early with poor prognosis. Hypoxiainducible factor- $1 \alpha$ (HIF- $1 \alpha$ ) is the most essential transcriptional regulator of hypoxia response. It has been well demonstrated that HIF-1 $\alpha$ extensively regulates hypoxia gene expression and aggressive phenotypes of cancer cells, leading to metabolic changes, increased survival, invasion, migration, angiogenesis, and other related signal transduction $[6,7]$. Recent studies have shown that overexpression of HIF- $1 \alpha$ is always detected in HCC and is associated with poor clinical outcomes [8-10]. RNA interference (RNAi), as a promising gene therapy method, has higher silencing efficiency and stability than traditional gene therapy and can target and interfere with pathogenic genes in a sequence-specific manner, providing more accurate and personalized treatment for a variety of life-threatening 
diseases $[11,12]$. Especially for malignant tumors, RNAi technology has significant advantages in controlling tumor growth, inhibiting tumor angiogenesis-related factors, and reducing tumor drug resistance [13]. The occurrence and development of many malignant tumors, including liver cancer, is the result of the accumulation of gene mutations and regulation of gene networks formed by the interaction of these mutated genes. Therefore, inhibiting the expression of these genes using RNAi technology may prevent the occurrence and development of HCC. With the deepening of research on the molecular mechanisms of HCC, an increasing number of genes have been found to be associated with this disease, which makes them targetable using RNAi technology. Hence, the application of gene interference technology to suppress HIF- $1 \alpha$-induced signaling pathways may be a novel strategy for HCC treatment.

Using gene targeted therapy, we innovatively explored whether we can combine modern medical technology with traditional Chinese medicine to achieve more effective prevention and treatment of tumors. Asparagus is a traditional Chinese herbal medicine that contains bioactive compounds such as flavonoids, lignans, steroids, and saponins, which are widely used in the treatment of breast cancer, malignant lymphoma, leukemia, and lung cancer [14]. Asparagus polysaccharide (ASP) is the main active component of asparagus and exerts antitumor and proapoptotic effects. In our previous study, we reported the effects of ASP on the growth, migration, invasion, and angiogenesis of HCC cells under hypoxia $[15,16]$. Based on the findings of previous studies, we continued to study the auxiliary role of ASPs in RNAi. This combined treatment has a dual targeting effect that may improve the local concentration of tumor drugs and transfection effect, thus increasing the sensitivity to gene therapy and achieving a more satisfactory antitumor effect. The results of this study can provide a theoretical basis for the introduction of gene therapy into clinical practice and a new perspective and breakthrough for the treatment of liver cancer and other tumors.

\section{Materials and Methods}

2.1. Cell Lines and Cell Culture. SK-Hep1 and Hep-3B cell lines and human umbilical vein endothelial cells (HUVECs) were purchased from the Type Culture Collection of the Chinese Academy of Sciences (Shanghai, China). Cells were divided into four groups: control group, ASP (24-h exposure)-treated group, HIF- $1 \alpha$ RNAi-treated group, and HIF$1 \alpha$ RNAi and ASP (24-h exposure)-treated group. All cells were maintained in DMEM (HyClone, Logan, USA) supplemented with $10 \%$ fetal bovine serum (FBS) (Gibco, South America) and $1 \%$ penicillin-streptomycin (Gibco). To establish hypoxia, SK-Hep1 and Hep-3B cells were cultured in a hypoxic incubator $\left(37^{\circ} \mathrm{C}, 5 \% \mathrm{CO}_{2}\right.$, and $\left.1 \% \mathrm{O}_{2}\right)$ for $24 \mathrm{~h}$. HUVECs were cultured in a normal oxygen incubator $\left(37^{\circ} \mathrm{C}\right.$, $5 \% \mathrm{CO}_{2}$, and $20 \% \mathrm{O}_{2}$ ).

2.2. ASP. ASP was purchased from Yuanye (Shanghai, China). DMEM was used to dilute ASP to $200 \mathrm{mg} / \mathrm{mL}$, and ASP was dissolved overnight on a shaking table at $4^{\circ} \mathrm{C}$. The next day, the supernatant liquid was centrifuged at $1000 \mathrm{rpm}$ for $5 \mathrm{~min}$, and the supernatant was filtered using 0.45 and $0.22 \mu \mathrm{m}$ filters and stored at $-20^{\circ} \mathrm{C}$ for long-term use.

2.3. Lentivirus and Plasmid Transfection. The adenovirus vector was amplified and packaged by Genechem (Shanghai, China). According to the manufacturer's instructions, SKHep1 and Hep-3B cells were cultured in a 6-well plate $1 \mathrm{~d}$ before the experiment. Then, shHIF $1 \alpha$ lentiviruses were transfected into SK-Hep1 and Hep-3B cells. These cells were cultured for 8-12 $\mathrm{h}$ to observe their state, and the medium was replaced with a fresh and complete medium. After infection for $72 \mathrm{~h}$, cells were observed under a fluorescence microscope and stably transfected cell lines were obtained after culturing in the medium containing puromycin $(2-3 \mathrm{~g} / \mathrm{mL})$ for 2 weeks. The shRNA targeting sequences for HIF- $1 \alpha$ were as follows: $5^{\prime}$-TGACAAGCCACCTGAGGAGA- ${ }^{\prime}$ and $5^{\prime}$-ACACGCGGAGAAGAGAAGGA-3'.

2.4. CCK-8 Cell Viability Assay. The CCK-8 assay was used to assess cell viability. Cells in 6-well plates were trypsinized to obtain a cell suspension and cultured at $1 \times 10^{4}$ cells/well in a 96-well plate. Each group was cultured in three wells, with another three wells (100 $\mu \mathrm{L}$ DMEM) serving as a blank control, and the 96-well plate was incubated in a hypoxic incubator $\left(37^{\circ} \mathrm{C}, 5 \% \mathrm{CO}_{2}, 1 \% \mathrm{O}_{2}\right)$ for $24 \mathrm{~h}$. Then, the medium was aspirated and discarded, and $10 \mu \mathrm{L}$ CCK- 8 proliferation reagent (Dojindo, Tokyo, Japan) and $90 \mu \mathrm{L}$ DMEM were added to each well. The absorbance (OD value) of each group was measured at $450 \mathrm{~nm}$ using an enzyme standard instrument (Thermo Fisher Scientific, Waltham, MA, USA). Cell viability was calculated as follows: cell activity inhibition rate $(\%)=(($ average OD value of the control group - average OD value of the experimental group)/(average OD value of the control group - average OD value of the blank group)) $\times$ $100 \%$.

2.5. Wound-Healing Assay. We performed a wound-healing assay to assess the cell migration ability. Cells in the logarithmic growth phase were cultured in a 6-well plate, and the next day, the cell density reached approximately $80 \%-$ $90 \%$. Two days after culture, the medium was aspirated, and a $20 \mu \mathrm{L}$ white pipette tip was drawn along a straight line in the center of the wells to form a single scratch. PBS (KeyGEN BioTECH, Jiangsu, China) was used to gently wash off the shed cells, leaving a clean scratch. Next, $2 \mathrm{~mL}$ DMEM containing ASP $(10 \mathrm{mg} / \mathrm{mL})$ was added to the wells, and $2 \mathrm{~mL}$ DMEM was added to the control group and HIF$1 \alpha$ RNAi-treated group followed by incubation for $24 \mathrm{~h}$. Scratched wells were photographed under an inverted microscope at $0 \mathrm{~h}$ and $24 \mathrm{~h}$ (migration rate $=$ scratch area at $0 \mathrm{~h} / \mathrm{scratch}$ area at $24 \mathrm{~h}$ ).

2.6. Transwell Invasion Assay. Cell invasion ability was assessed using transwell assays. Matrigel $(10.5 \mathrm{mg} / \mathrm{mL} ; \mathrm{BD}$ Biosciences, San Jose, CA, USA) diluted to $1 / 4$ in DMEM was spread in the upper compartment of the transwell 
$(100 \mu \mathrm{L} /$ well $)$ and placed in an incubator for coagulation. Meanwhile, $500 \mu \mathrm{L}$ DMEM (20\% FBS) was added to the lower chambers of the transwell. Then, $1 \times 10^{5}$ cells from each group were added to the upper compartment, incubated for $48 \mathrm{~h}$, fixed with 95\% ethanol, stained with crystal violet, and photographed under a light microscope, and the number of invading cells was calculated.

2.7. HUVEC Tube Formation Assay. Supernatants were collected from the four groups of cells cultured for $24 \mathrm{~h}$, centrifuged, and stored at $-20^{\circ} \mathrm{C}$ for subsequent use. HUVECs were resuspended in the supernatant at $2.5 \times 10^{4}$ cells $/ 100 \mu \mathrm{L}$. Next, $50 \mu \mathrm{L}$ of Matrigel was added to each well. After incubation at $37^{\circ} \mathrm{C}$ for $30 \mathrm{~min}, 100 \mu \mathrm{L}$ of resuspended HUVECs was added to the wells and incubated at $37^{\circ} \mathrm{C}$ for 4-6 h. Cells were stained with calcein (Invitrogen, Carlsbad, CA, USA) for $30 \mathrm{~min}$ at $37^{\circ} \mathrm{C}$. The formation of capillary-like structures was photographed, and Image J software (Image J 1.4; National Institutes of Health, Bethesda, USA) was used to analyze the tube number.

2.8. RNA Purification and $q P C R$ Assay. Total RNA was extracted from SK-Hep1 and Hep-3B cells using TRIzol reagent (Thermo Fisher Scientific). A qRT-PCR kit (Takara, Shiga, Japan) and $0.5 \mu \mathrm{g}$ total RNA were used to perform qRT-PCR. All primers were synthesized by Sangon Biotech (Shanghai, China): GAPDH forward, 5'-CAGGAGGCATTGCTGATGAT- $3^{\prime}$, and reverse, $5^{\prime}$-GAAGGCTGGGGCTCATTT- ${ }^{\prime}$; HIF- $1 \alpha$ forward, $5^{\prime}$-TGACAAGCCACCTGAGGAGA- ${ }^{\prime}$, and reverse, $5^{\prime}$-ACACGCGGAGAAGAGAAGGA-3'; VEGF forward, 5' ${ }^{\prime}$ TACCTCCACCATGCCAAGTG- $3^{\prime}$, and reverse, $5^{\prime}$ GGTCTCGATTGGATGGCAGT-3' .

2.9. Western Blotting Assay. Cells at a density of $3 \times 10^{5}$ cells/ well were incubated overnight in a 6-well plate. After incubation with different drugs for $24 \mathrm{~h}$, RIPA lysis buffer containing a protease inhibitor and phenylmethylsulfonyl fluoride (Beyotime BioTECH, Shanghai, China) was used for cell lysis on ice for $30 \mathrm{~min}$. Protein concentration was determined using a BCA assay kit (Beyotime BioTECH). Protein samples were added to a protein-loading buffer (Beyotime BioTECH), boiled at $100^{\circ} \mathrm{C}$ for $8 \mathrm{~min}$, separated using polyacrylamide gel electrophoresis (Epizyme, Shanghai, China), and transferred to a polyvinylidene fluoride membrane (Millipore, Massachusetts, USA). The membrane was sealed with a rapid blocking solution (Beyotime BioTECH) for $30 \mathrm{~min}$ at room temperature and then incubated with primary antibodies (diluted at $1: 1000$ ) at $4^{\circ} \mathrm{C}$ overnight. Antibodies against HIF- $1 \alpha$, VEGF, AKT, p-AKT, ERK, and p-ERK were purchased from CST (Boston, USA). Secondary antibodies labeled with horseradish peroxidase (KeyGEN BioTECH) were then incubated (diluted at $1: 1500$ ) at room temperature for $1 \mathrm{~h}$. Finally, an ECL chromogenic solution (Beyotime BioTECH) was prepared and dropped on the membrane surface, which was exposed and photographed.
2.10. Animal Studies. Twenty male nude mice (Balb/c) (SLAC Laboratory Animal, Shanghai, China) aged 5 weeks were subcutaneously inoculated with $100 \mu \mathrm{L}$ of PBS containing $5 \times 10^{6} \mathrm{SK}-\mathrm{Hep} 1$ cells. The mice were divided into the following groups $(n=5)$ : (1) control group, inoculated with normal SK-Hep1 cells and treated with normal saline after tumor formation; (2) ASP group, inoculated with normal SK-Hep1 cells and treated with $100 \mathrm{mg} / \mathrm{kg}$ ASP (by gavage) after tumor formation; (3) HIF- $1 \alpha$ RNAi group, inoculated with HIF- $1 \alpha$ RNAi-treated SK-Hep1 cells and treated with normal saline after tumor formation; and (4) HIF- $1 \alpha$ RNAi + ASP group, inoculated with HIF- $1 \alpha$ RNAi-treated SK-Hep1 cells and treated with $100 \mathrm{mg} / \mathrm{kg}$ ASP (by gavage) after tumor formation. Tumor volume and body weight were measured daily after the inoculation. Then, the tumor tissues were harvested, embedded, fixed, and prepared for immunohistochemical (IHC) staining and western blotting. All animal experiments performed in this study were carried out under specific pathogen-free conditions and conformed to the requirements of the Animal Ethics Committee.

2.11. Statistical Analysis. Each experiment was performed in triplicate. Statistical analyses were performed using the GraphPad Prism, version 8.0. Data (GraphPad Software, San Diego, CA, USA) are expressed as the mean \pm SEM. Differences between the groups were estimated using one-way analysis of variance (ANOVA). Statistical significance was set at $P<0.05$.

\section{Results}

3.1. HIF-1 $\alpha$ RNAi Combined with ASP Inhibited HCC Cell Proliferation. In our previous study [16], we confirmed that different concentrations of ASP inhibited the proliferation of HCC cells. In the present study, based on the IC50 of ASP (12.81 mg/mL for SK-Hep1 and $9.04 \mathrm{mg} / \mathrm{mL}$ for Hep-3B), we selected $10 \mathrm{mg} / \mathrm{mL}$ ASP for experiments on the combined effect of ASP and HIF-1 $\alpha$ RNAi on SK-Hepl and Hep$3 \mathrm{~B}$ cell proliferation. Compared with the ASP-treated group or HIF- $1 \alpha$ RNAi-treated group, the proliferation of both cell lines was significantly inhibited by the combination of Asp and HIF-1 $\alpha$ RNAi. (Figure 1(c)).

\subsection{HIF-1 $\alpha$ RNAi Combined with ASP Inhibited the Migration} and Invasion of HCC Cells. To assess the inhibitory effect of ASP combined with HIF- $1 \alpha$ RNAi on migration and invasion, we treated HCC cells (SK-Hep1 and Hep-3B) with HIF- $1 \alpha$ RNAi for $24 \mathrm{~h}$ (migration) or $48 \mathrm{~h}$ (invasion) together with ASP at $10 \mathrm{mg} / \mathrm{mL}$. The results showed that compared with the control group, the migration ability of cells was decreased after treatment with ASP or HIF- $1 \alpha$ RNAi alone, and the effect was similar in both groups, indicating that ASP or HIF- $1 \alpha$ RNAi could affect the migration ability of HCC cells. However, the migration ability of cells in the group treated with HIF- $1 \alpha$ RNAi combined with ASP was further inhibited compared with that of cells treated with ASP or HIF-1 $\alpha$ RNAi alone (Figures 1(a), 1(b), 2(a), and 2(b)). In terms of invasion ability, cells in the control 

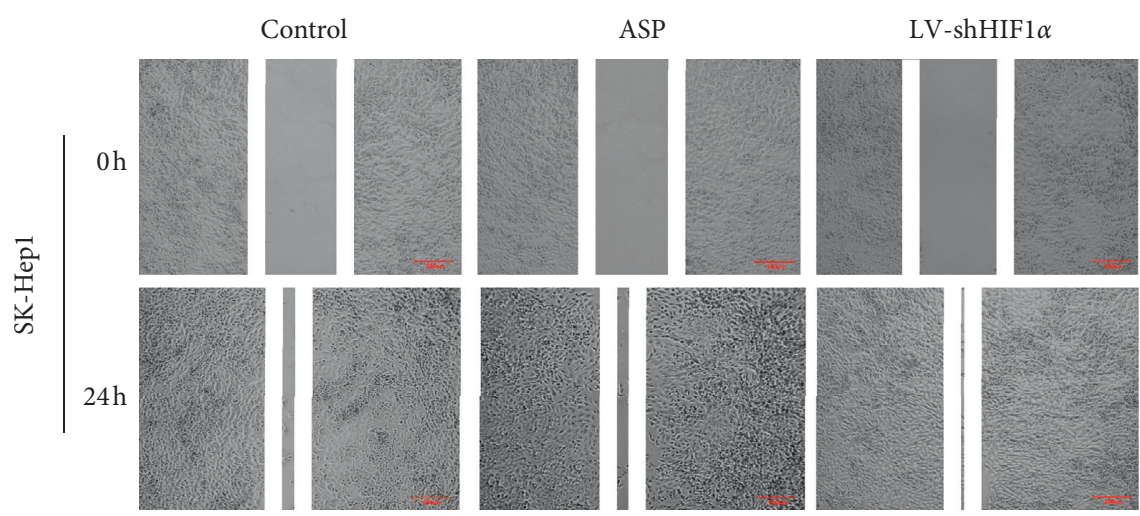

LV-shHIF $1 \alpha+$ ASP
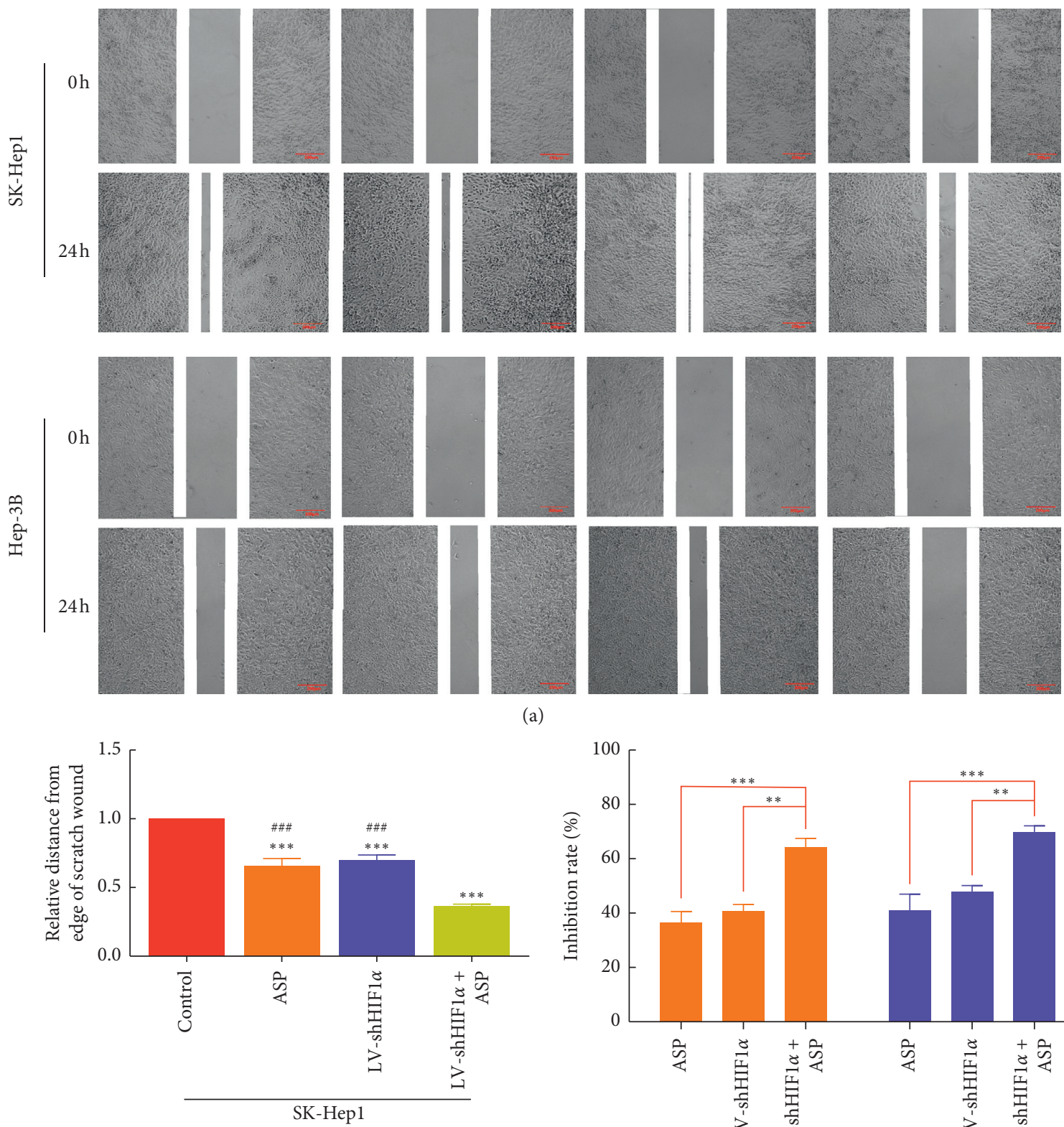

(a)
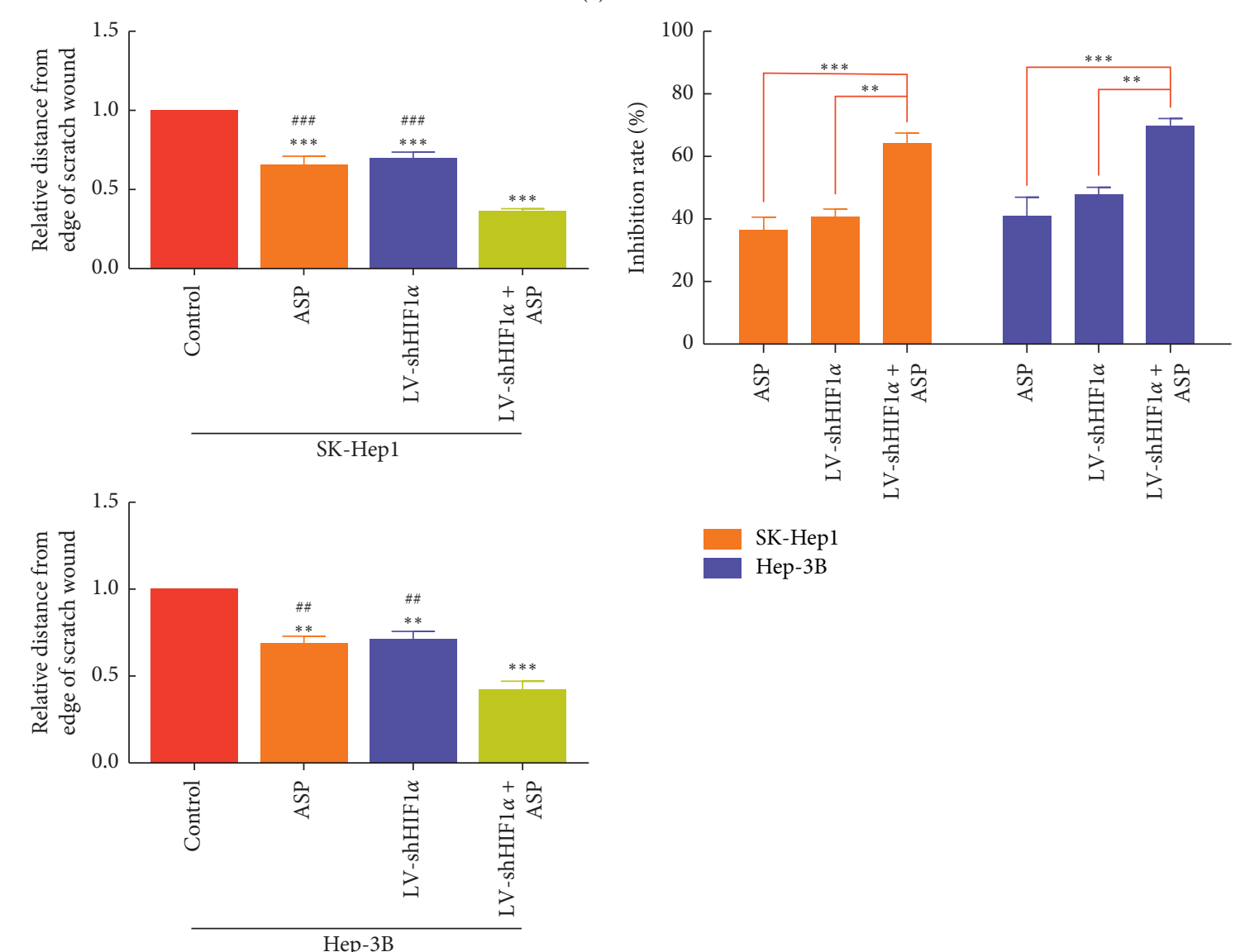

SK-Hep1

Hep-3B

(b)

(c)

FIgUre 1: Effect of HIF- $1 \alpha$ RNAi combined with ASP on the proliferation and migration of SK-Hep1 and Hep-3B cells. (a)-(b) Migration of HCC cells. ${ }^{* *} P<0.01$ and ${ }^{* *} P<0.001$ versus control group. ${ }^{\# \#} P<0.01$ and ${ }^{\# \# \#} P<0.001$ versus LV-shHIF $1 \alpha+$ ASP group. (c) Proliferation of HCC cells. ${ }^{* *} P<0.01$ and ${ }^{* * *} P<0.001$ versus LV-shHIF $1 \alpha+$ ASP group. 
group had a strong ability to penetrate transwell chambers, whereas the invasion ability of the cells in the group treated with ASP or HIF- $1 \alpha$ RNAi group was decreased. In addition, cells treated with HIF- $1 \alpha$ RNAi and ASP were significantly less invasive than those treated with ASP or HIF- $1 \alpha$ RNAi (Figures 2(a) and 2(b)).

3.3. HIF-1 $\alpha$ RNAi Combined with ASP Inhibited HCC CellInduced HUVEC Tube Formation. To analyze the combined effect of ASP and HIF- $1 \alpha$ RNAi on HUVEC tube formation induced by HCC cells, we conducted a HUVEC-simulated angiogenesis test. HUVECs were cultured on matrix gel and migrated to form a capillary structure with lumen, simulating vascularization. Our results showed that HUVECs cultured in the supernatant of ASP-treated or HIF- $1 \alpha$ RNAitreated HCC cells (SK-Hep1 and Hep-3B) presented significantly reduced tubular formation capacity compared with HUVECs cultured in control HCC cell culture supernatant. Consistently, the supernatant of HCC cells undergoing combined treatment with HIF- $1 \alpha$ RNAi and ASP induced further inhibition, with HUVECs cultured in this supernatant forming less firm capillary and cord structures (Figures 2(c) and 2(d)).

3.4. HIF-1 $\alpha$ RNAi Combined with ASP Inhibited the Expression of HIF- $1 \alpha$ and VEGF in HCCCells. To verify whether the mechanism of ASP combined with HIF- $1 \alpha$ RNAi inhibiting the proliferation, migration, invasion, and angiogenesis of HCC cells was correlated with HIF- $1 \alpha$ and VEGF levels, the expression of HIF- $1 \alpha$ and VEGF was assessed using qPCR (Figure 3(a)) and western blotting (Figures 3(b) and 3(c)). The results showed that compared with the control group, the mRNA and protein expression of HIF- $1 \alpha$ and VEGF in the ASP-treated group or HIF- $1 \alpha$ RNAi-treated group was downregulated, while that in the HIF-1 $\alpha$ RNAi and ASP combined treatment group was lower than that in the other two groups.

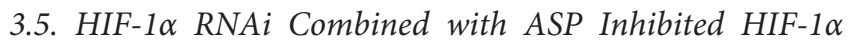
Expression in Human HCC Cells by Regulating the PI3K and MAPK Signaling Pathways. MAPK and PI3K are known to play important roles in regulating HIF- $1 \alpha$ protein expression. Therefore, inhibition of the MAPK and PI3K signaling pathways may prevent its expression. Previous experiments have confirmed that HIF- $1 \alpha$ RNAi combined with ASP treatment inhibits the expression of HIF- $1 \alpha$ and VEGF proteins. To clarify whether this effect was achieved by inhibiting the MAPK and PI3K signaling pathways, we evaluated the protein levels of AKT, p-AKT, ERK, and p-ERK (involved in the MAPK and PI3K signaling pathways) in SK-Hep1 and Hep-3B cells $24 \mathrm{~h}$ after treatment with ASP and/or HIF-1 $\alpha$ RNAi. The results showed that the combined treatment significantly downregulated p-AKT and p-ERK in both cell lines but had no significant effect on the levels of AKT and ERK (Figures 3(b) and 3(c)), suggesting that HIF- $1 \alpha$ RNAi and ASP regulate the expression of HIF$1 \alpha$ in HCC cells by inhibiting the MAPK and PI3K signaling pathways, thereby inhibiting the migration, invasion, and angiogenesis of these cells.

3.6. HIF-1 $\alpha$ RNAi Combined with ASP Inhibited Tumor Growth in a Subcutaneous Xenograft Mouse Model. We further investigated the effect of HIF- $1 \alpha$ RNAi combined with ASP on HCC in vivo. Based on the above-mentioned results, the anticancer effect of HIF- $1 \alpha$ RNAi combined with ASP was more obvious in SK-Hepl cells than in Hep-3B cells. Therefore, the former were selected to further study the effect of the combined treatment in a subcutaneous xenograft model using nude mice. SK-Hep1 cells $\left(5 \times 10^{6}\right)$ were subcutaneously inoculated into the armpits of mice to produce tumors. After tumor formation, the ASP and HIF-1 $\alpha$ RNAi + ASP groups were administered ASP gastrically $(100 \mathrm{mg} / \mathrm{kg})$ every day for 3 consecutive weeks. Compared with the control group, the ASP and HIF- $1 \alpha$ RNAi groups showed inhibited tumor growth and reduced tumor weight. Furthermore, HIF-1 $\alpha$ RNAi + ASP significantly inhibited tumor growth and reduced tumor weight (Figures 4(a), 4(b) and 4(d)).

3.7. HIF-1 $\alpha$ RNAi Combined with ASP Inhibited Angiogenesis in Subcutaneous HCC Xenografts in Nude Mice. To further clarify the mechanism by which HIF- $1 \alpha$ RNAi + ASP inhibits the growth of subcutaneously transplanted HCC tumors in nude mice, IHC staining was performed in tumors from all groups (HIF- $1 \alpha \mathrm{RNAi}+\mathrm{ASP}$, HIF- $1 \alpha$ RNAi, ASP, and control), and the expression of HIF-1 $\alpha$, VEGF, and CD34 in tumors was assessed. The results of IHC staining showed that, compared with the HIF- $1 \alpha$ RNAi or ASP groups, the staining intensity of VEGF and CD34 in tumors from the HIF- $1 \alpha$ RNAi + ASP group was significantly decreased (Figures 5(a) and 5(b)). These results indicate that inhibition of subcutaneous xenograft growth by HIF- $1 \alpha$ $\mathrm{RNAi}+\mathrm{ASP}$ was correlated with the inhibition of angiogenesis in HCC tissues in nude mice.

3.8. HIF-1 $\alpha$ RNAi Combined with ASP Prevented Angiogenesis in Subcutaneous HCC Xenografts in Nude Mice by Inhibiting the MAPK and PI3K Signaling Pathways. Current studies have confirmed that the activation of the MAPK and PI3K signaling pathways promotes the expression of HIF- $1 \alpha$, induces the production of downstream VEGF, promotes tumor angiogenesis, and indirectly promotes tumor growth $[17,18]$. The above in vitro studies also confirmed that HIF$1 \alpha$ RNAi combined with ASP inhibits the expression of proteins related to the MAPK and PI3K signaling pathways in HCC cells. To further verify the mechanism by which HIF- $1 \alpha$ RNAi combined with ASP inhibits angiogenesis in subcutaneously transplanted HCC in nude mice, the expression of HIF- $1 \alpha$, VEGF, AKT, p-AKT, ERK, and p-ERK was assessed using western blotting. The results showed that compared with the HIF- $1 \alpha$ RNAi or ASP group, protein levels of HIF- $1 \alpha$ and VEGF in tumors from nude mice transplanted with HIF-1 $\alpha$ RNAi-treated cells were significantly downregulated (Figures 4(c) and 4(e)). Western blot results also showed that compared with the ASP-treated 

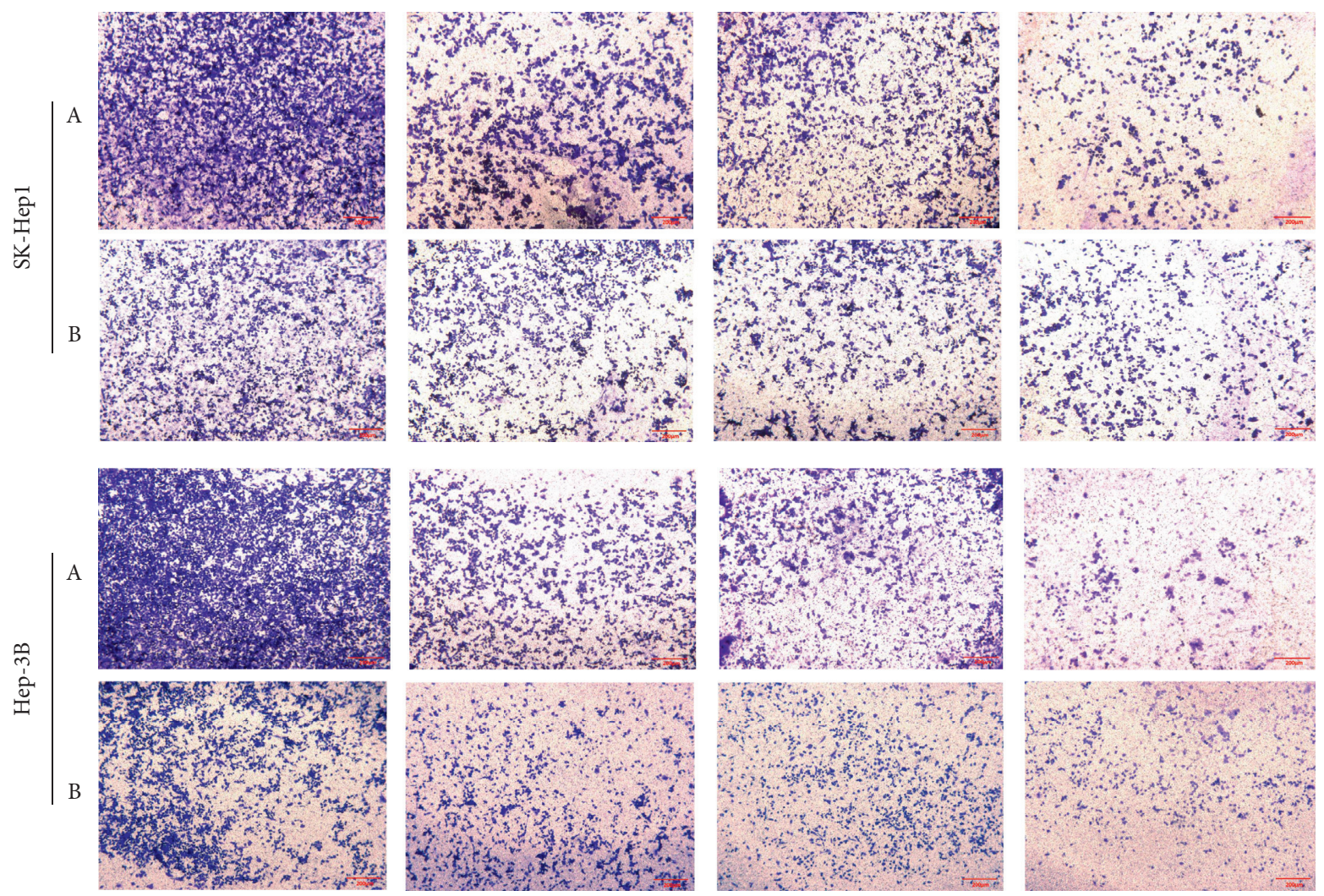

(a)
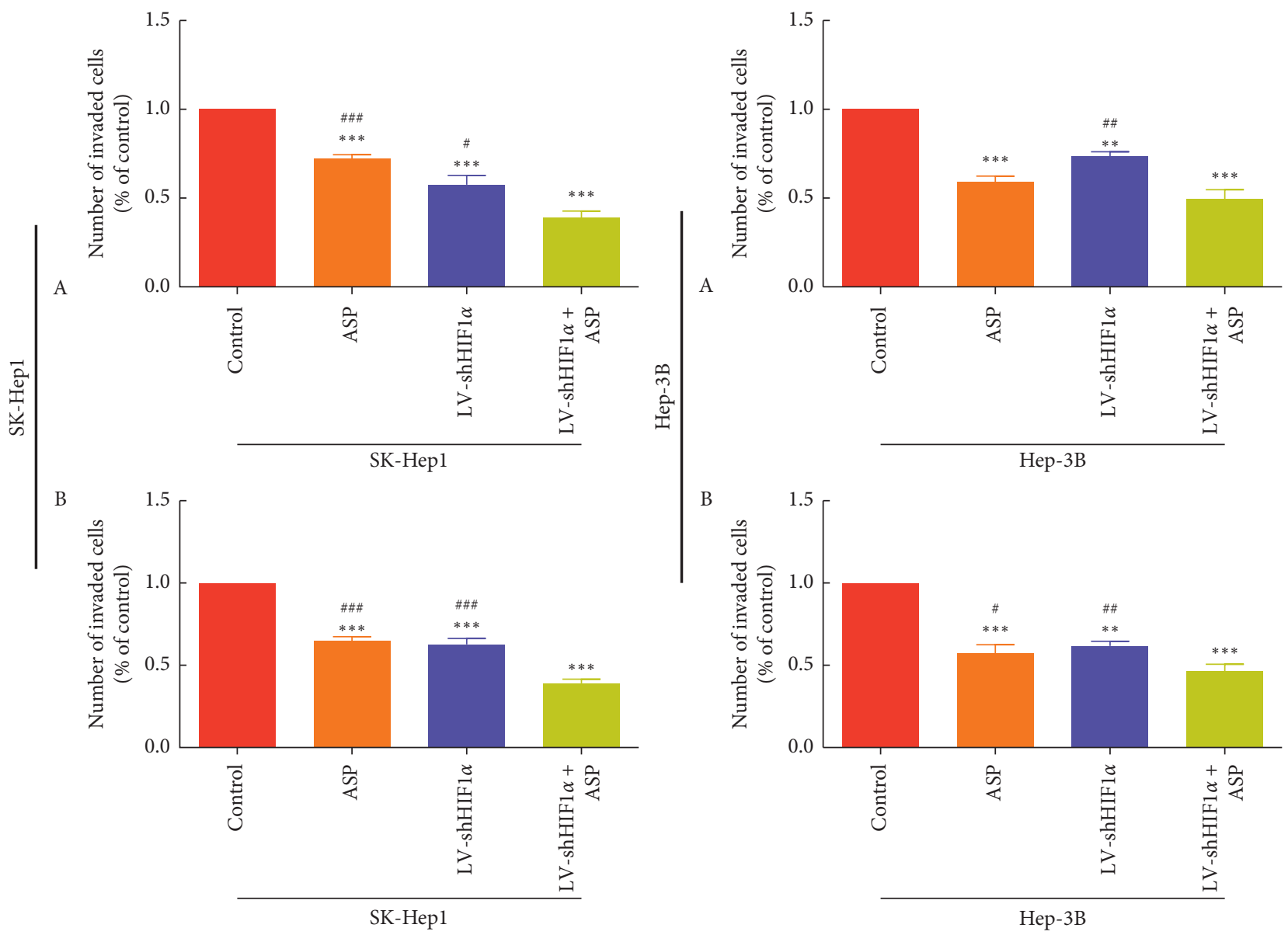

(b)

Figure 2: Continued. 

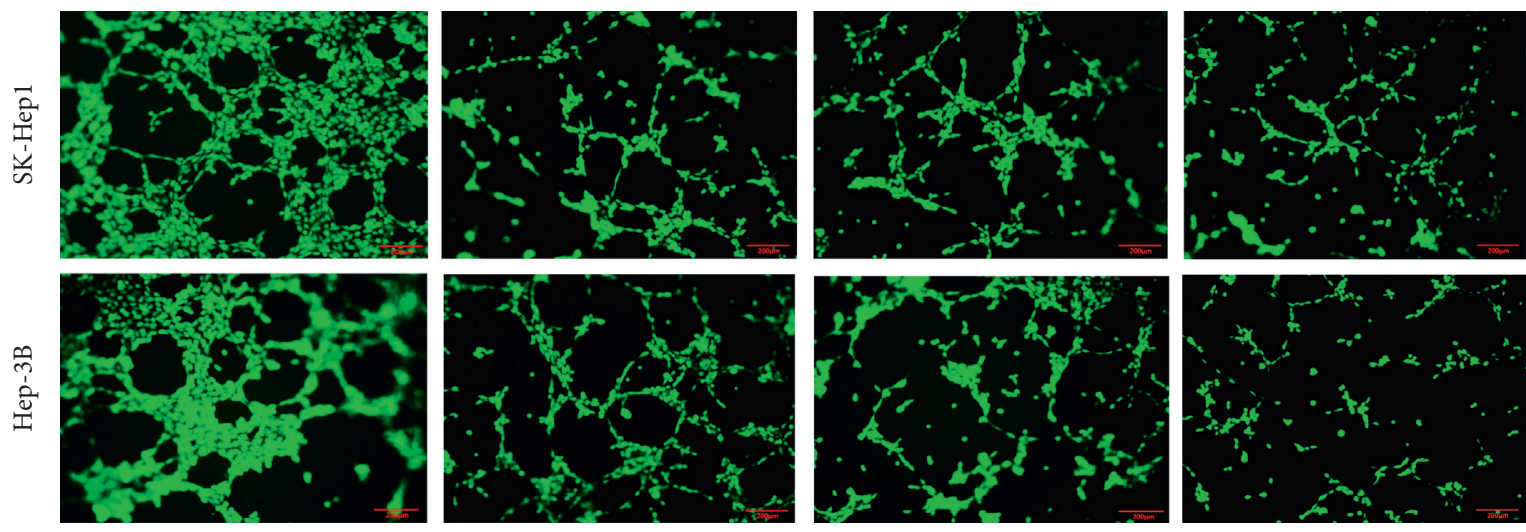

(c)
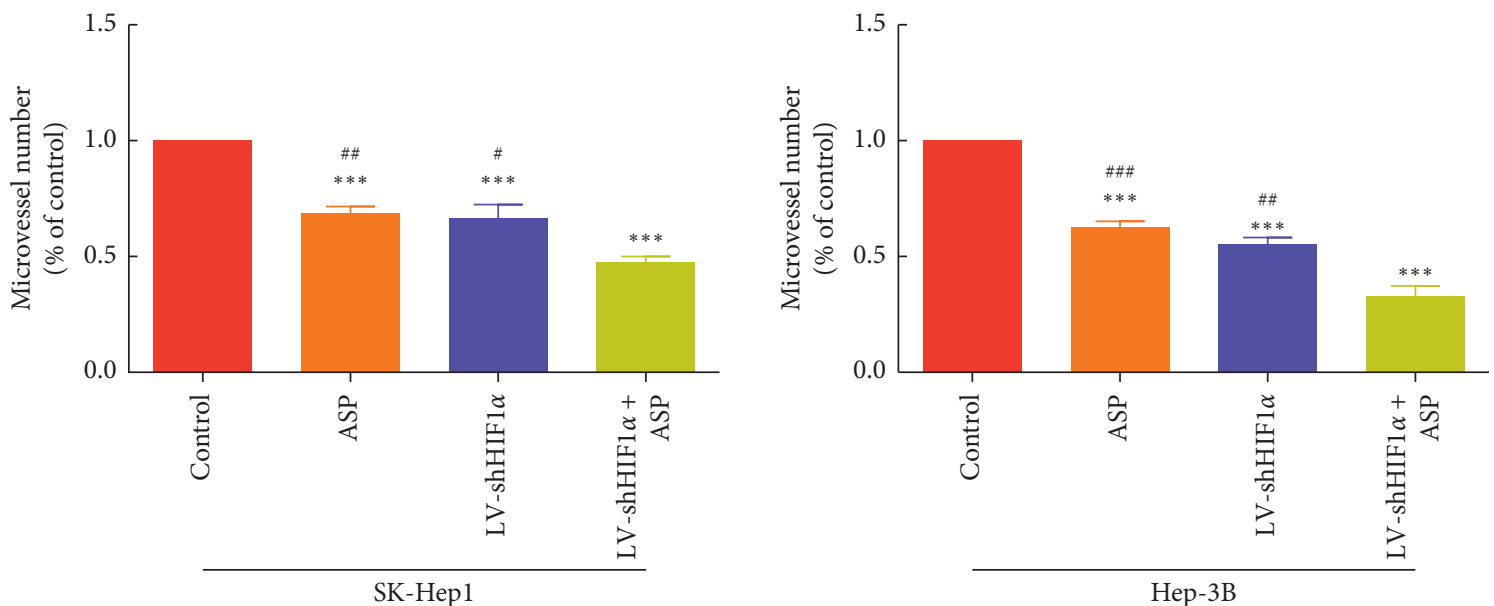

(d)

Figure 2: Effect of HIF-1 $\alpha$ RNAi combined with ASP on the migration and angiogenesis of SK-Hep1 and Hep-3B cells. (a)-(b) Invasion of HCC cells (A. transwell assay; B. transwell invasion assay with Matrigel). ${ }^{* *} P<0.01$ and ${ }^{* * *} P<0.001$ versus control group. ${ }^{\#} P<0.05$, ${ }^{\# \#} P<0.01$, and ${ }^{\# \# \#} P<0.001$ versus LV-shHIF1 $\alpha+$ ASP group. (c)-(d) Angiogenesis of HCC cells. ${ }^{* * *} P<0.001$ versus control group. ${ }^{\#} P<0.05$, \#\# $P<0.01$, and ${ }^{\# \# \# ~} P<0.001$ versus LV-shHIF $1 \alpha+$ ASP group.
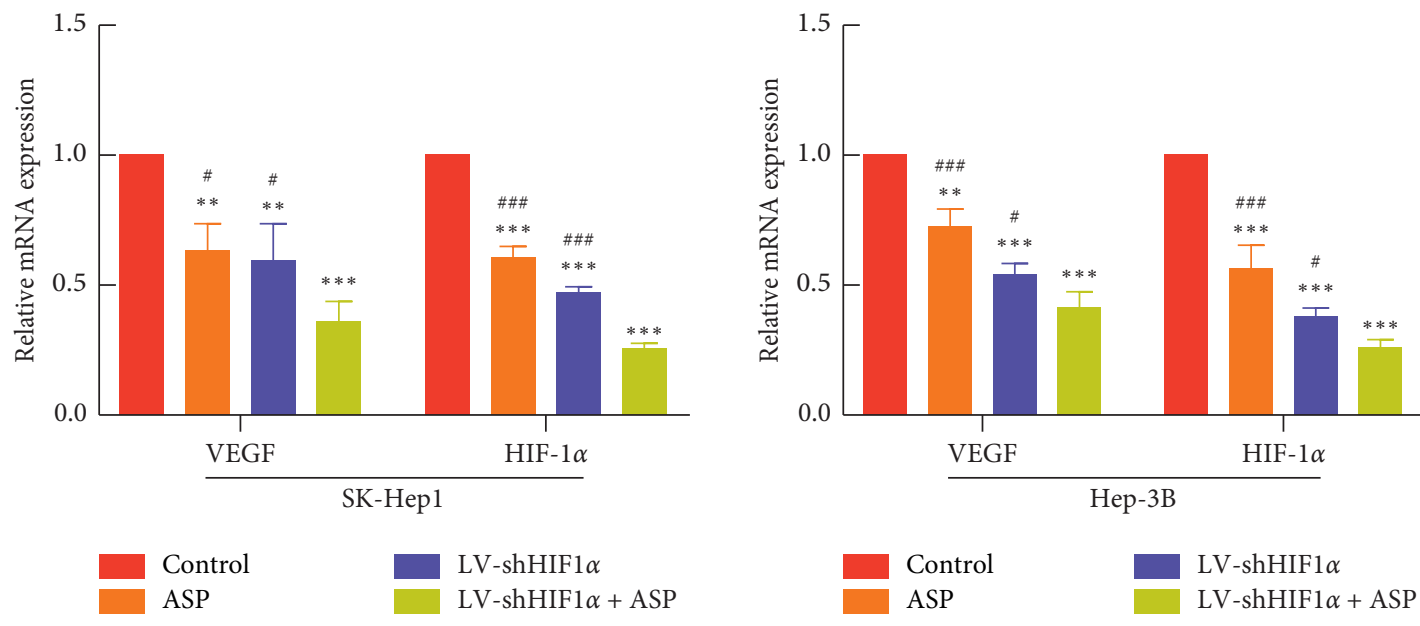

(a)

FIgUre 3: Continued. 


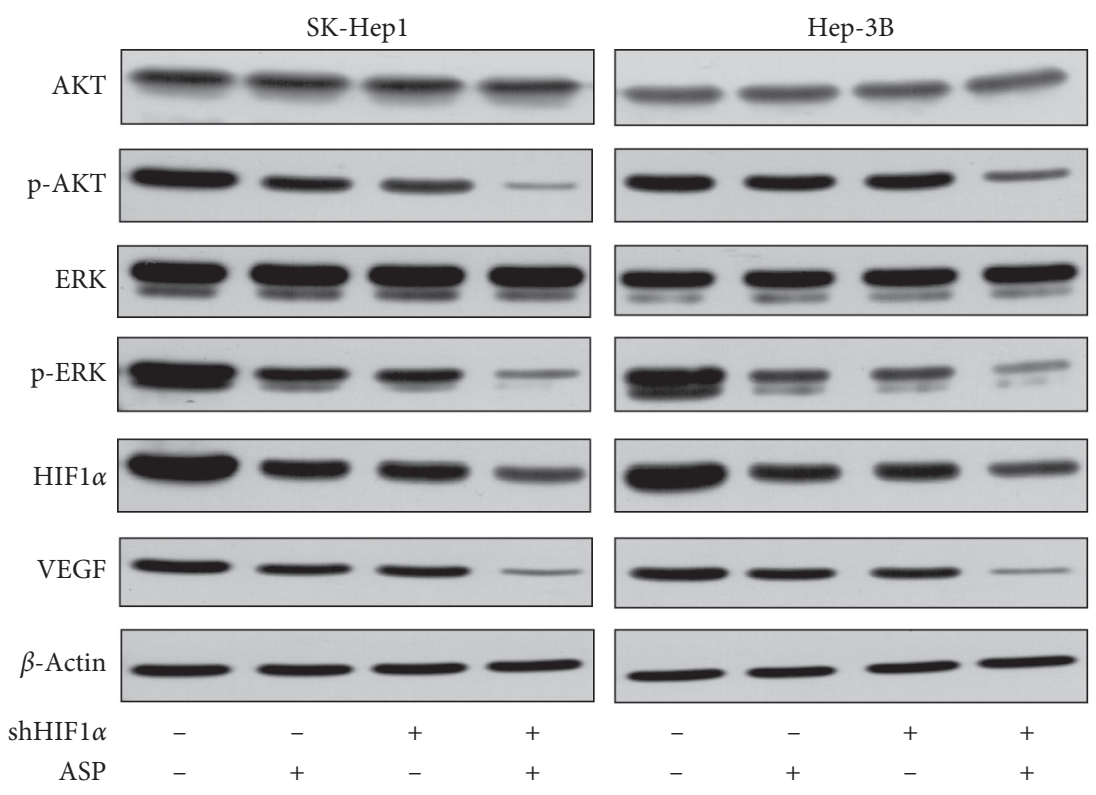

(b)
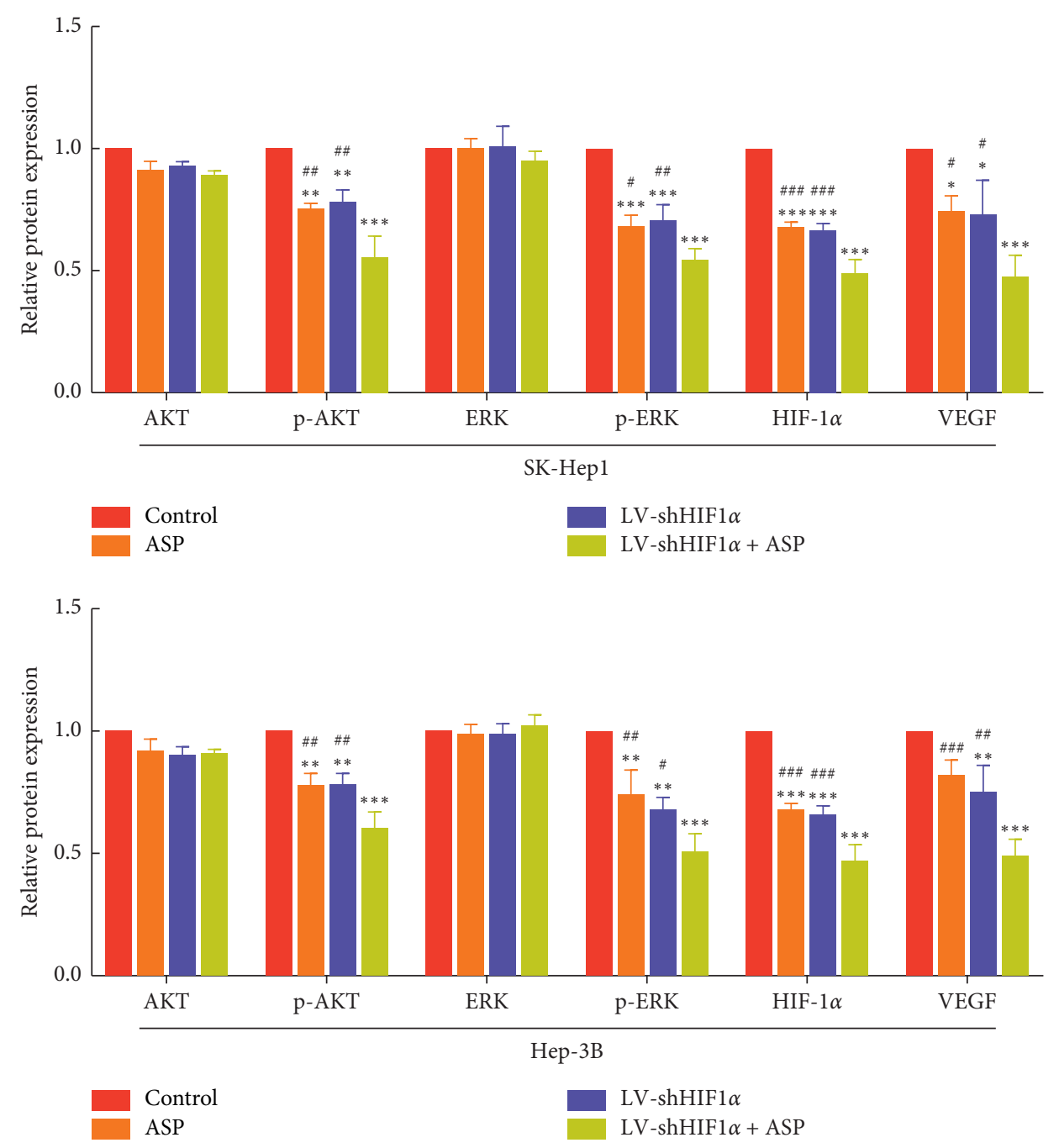

(c)

FIgURE 3: Effect of HIF- $1 \alpha$ RNAi combined with ASP on the expression of MAPK and PI3K signaling pathway-related proteins. (a) Relative expression of HIF- $1 \alpha$ and VEGF mRNA analyzed using qPCR. ${ }^{* *} P<0.01$ and ${ }^{* * *} P<0.001$ versus control group. ${ }^{\#} P<0.05$, ${ }^{\# \#} P<0.01$, and \#\#\# $P<0.001$ versus LV-shHIF1 $\alpha+$ ASP group. (b)-(c) Protein levels of HIF-1 $\alpha$, VEGF, AKT, p-AKT, ERK, and p-ERK assessed using western blot. ${ }^{*} P<0.05,{ }^{* *} P<0.01$, and ${ }^{* * *} P<0.001$ versus control group. ${ }^{\#} P<0.05,{ }^{\# \#} P<0.01$, and ${ }^{\# \# \#} P<0.001$ versus LV-shHIF1 $\alpha+$ ASP group. 


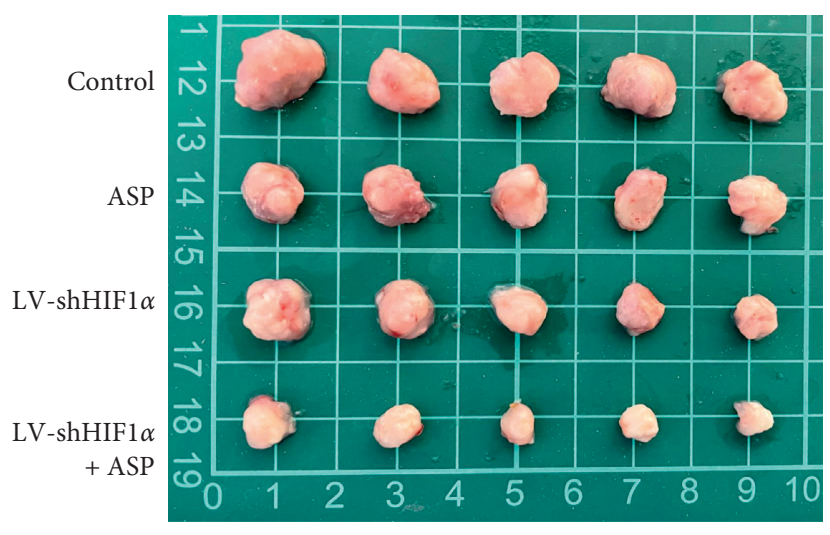

(a)

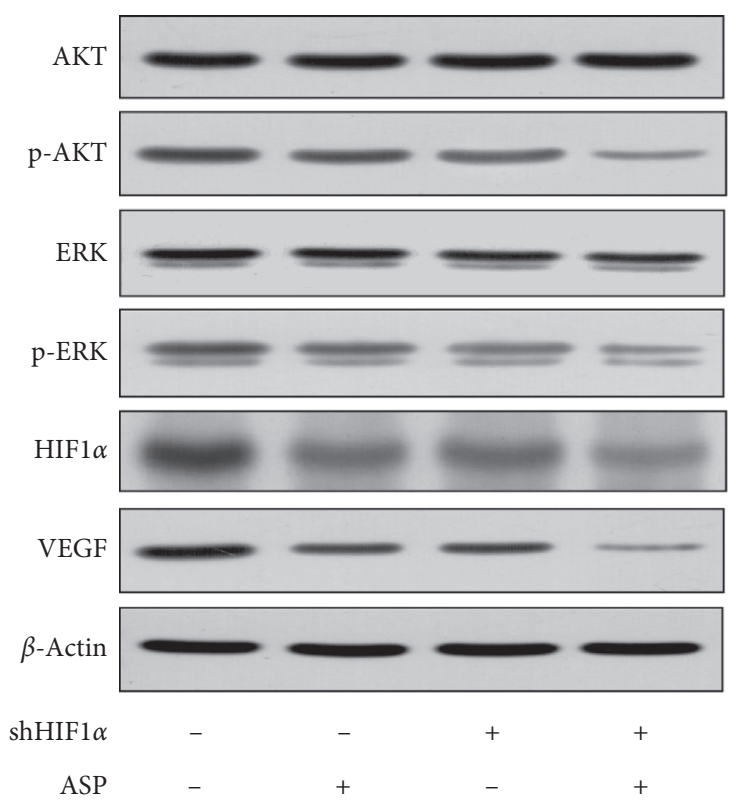

(c)

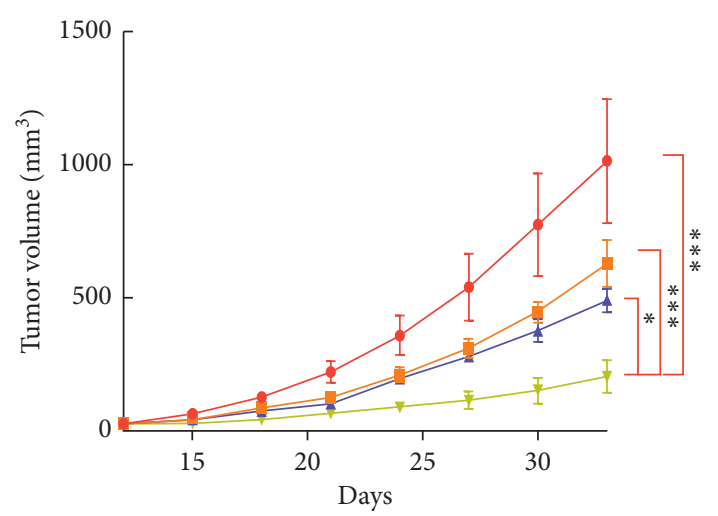

$\rightarrow$ Control $\rightarrow$ LV-shHIF $1 \alpha$

- ASP $\rightarrow$ LV-shHIF1 $\alpha+$ ASP

(b)

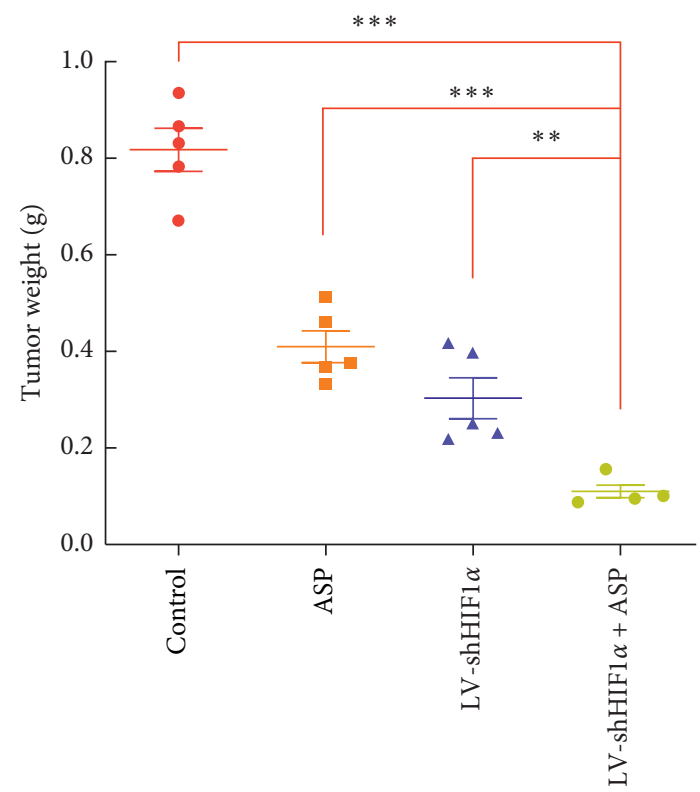

(d)

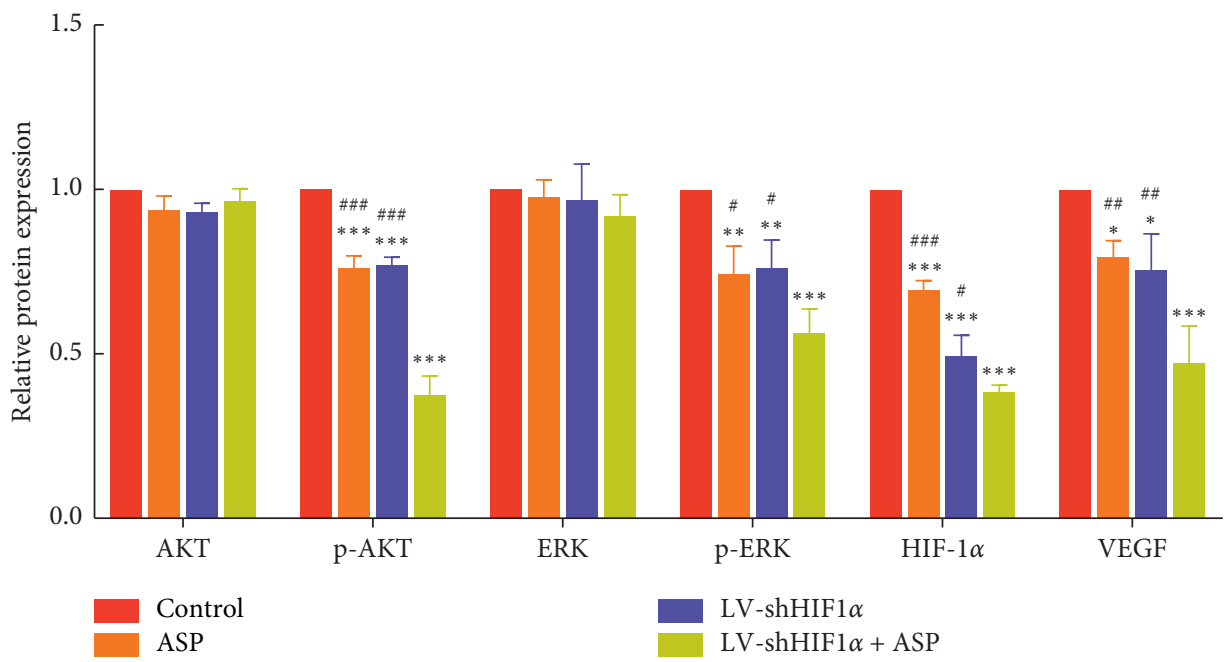

(e)

FIgURE 4: Effect of HIF- $1 \alpha$ RNAi combined with ASP on HCC growth and angiogenesis in a SK-Hep1 xenograft nude mouse model. (a)-(b), (d) Tumor volume and weight. ${ }^{*} P<0.05,{ }^{* *} P<0.01$, and ${ }^{* * *} P<0.001$ versus LV-shHIF1 $\alpha+$ ASP group. (c), (e) Protein levels of HIF- $1 \alpha$, VEGF, AKT, p-AKT, ERK, and p-ERK assessed using western blot. ${ }^{*} P<0.05,{ }^{* *} P<0.01$, and ${ }^{* * *} P<0.001$ versus control group. ${ }^{\#} P<0.05$, ${ }^{\# \#} P<0.01$, and ${ }^{\# \# \#} P<0.001$ versus LV-shHIF $1 \alpha+$ ASP group. 

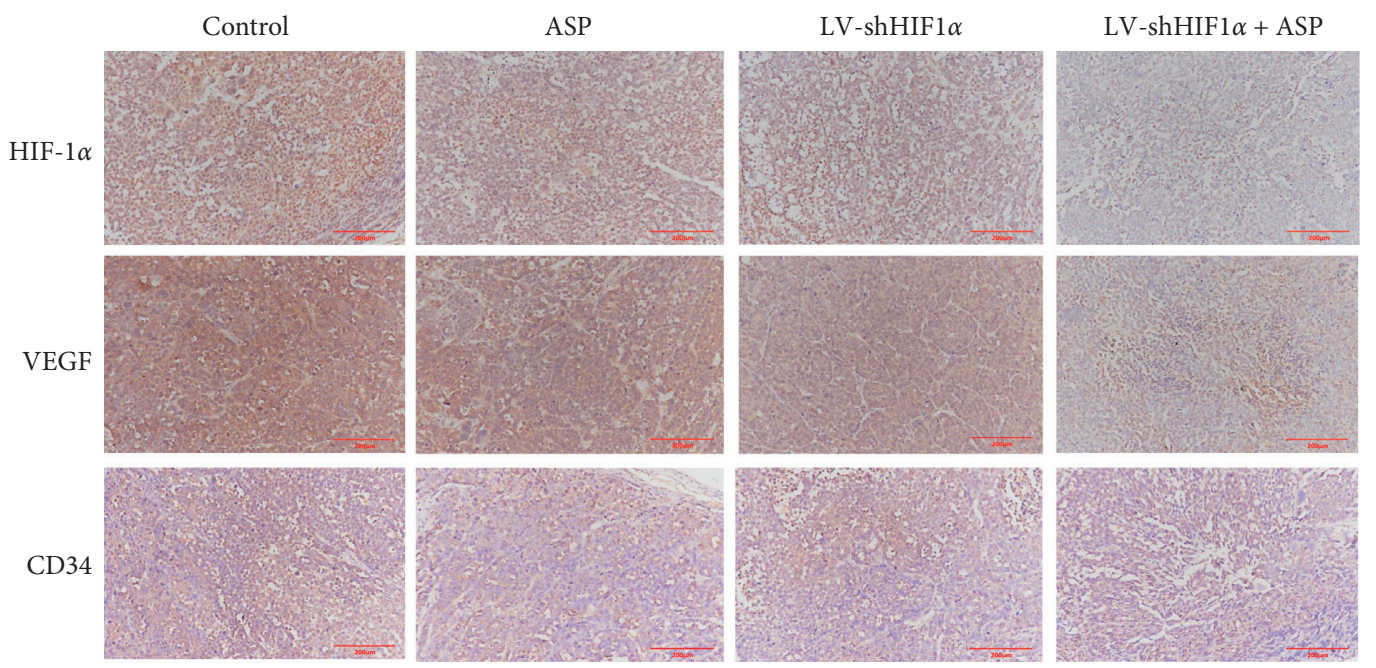

(a)

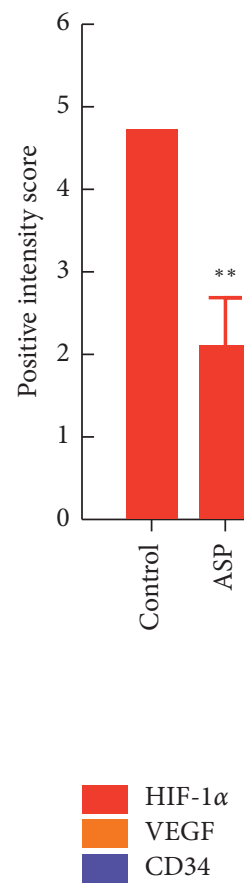

(a)

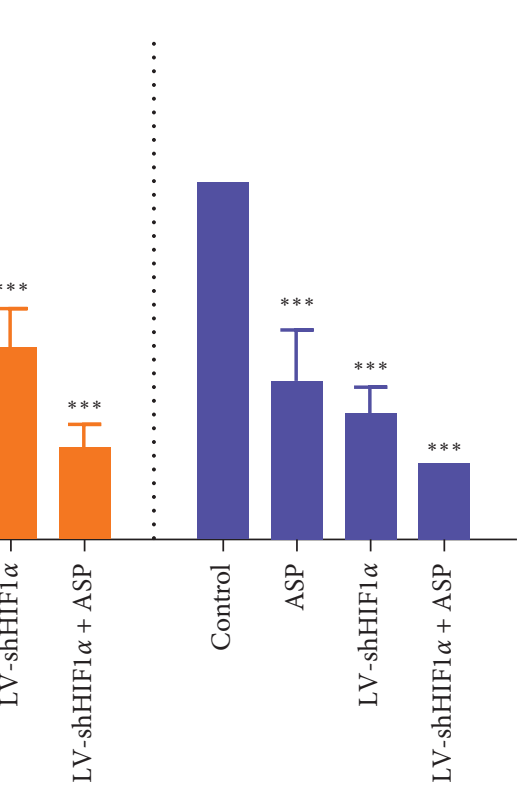

VEGF

(b)

FIGURE 5: Effect of HIF- $1 \alpha$ RNAi combined with ASP on the expression of HIF- $1 \alpha$, VEGF, and CD34 in subcutaneously transplanted tumors assessed using immunohistochemistry. ${ }^{* *} P<0.01$ and ${ }^{* * *} P<0.001$ versus control group. ${ }^{\# \#} P<0.01$ versus LV-shHIF1 $\alpha+$ ASP group.

group or the HIF- $1 \alpha$ RNAi-treated group, the levels of p-AKT and p-ERK in tumors from the HIF- $1 \alpha$ RNAi + ASP group were significantly downregulated, but those of AKT and ERK remained the same (Figures 4(c) and 4(e)). These results indicate that HIF- $1 \alpha$ RNAi + ASP inhibits angiogenesis in nude mice subcutaneously transplanted with HCC, possibly by inhibiting the MAPK and PI3K signaling pathways.

\section{Discussion}

HCC is one of the most common malignant tumors worldwide and a major cause of cancer-related deaths with poor prognosis $[19,20]$. Although many studies have focused on the cellular and molecular mechanisms underlying HCC, current therapies are still inadequate, and there is a long way to go before the desired therapeutic effect on HCC can be clinically achieved; thus, more effective therapies need to be developed. Asparagus is a traditional Chinese herbal medicine used in China that contains bioactive compounds such as flavonoids, lignans, steroids, and saponins, which are widely used in the treatment of breast cancer, malignant lymphoma, leukemia, and lung cancer. ASP is one of the main components of aspartame extract, which improves immunity and liver function [21]. In our previous study, we demonstrated that ASP, a Chinese herbal extract, inhibited HIF- $1 \alpha$-mediated angiogenesis under 
hypoxic conditions [16]. Based on this, we silenced the HIF$1 \alpha$ gene using RNAi to determine the effect of RNAi technology combined with ASP on cancer angiogenesis and provide an experimental basis for comprehensive clinical anticancer therapy using such combinations.

Hypoxia is the most common microenvironmental feature of many solid tumors, including HCC [22, 23], and is a key factor in the occurrence, prognosis, and metastasis of liver cancer [24]. HIF is a transcription factor that helps cells sense and adapt to changes in oxygen levels [25]. The HIF-1 $\alpha$-related signal transduction pathway is one of the most important pathways in HCC angiogenesis and is also the main signaling pathway that induces VEGF [26]. Under normoxic conditions, HIF-1 $\alpha$ nucleosides are hydroxylated and rapidly degraded through the ubiquitin-proteasome pathway, whereas under hypoxia, HIF- $1 \alpha$ is no longer degraded, enters the nucleus, and binds to HIF- $1 \alpha$ protein kinase, thereby activating downstream gene transcription [27]. Furthermore, HIF- $1 \alpha$-mediated HCC angiogenesis may be affected by the upstream AKT pathway [28] and AKT in PI3K under the condition of phosphorylation and activation of AKT kinase, further activating the mechanistic target of rapamycin (mTOR). In turn, this stimulates the expression of HIF- $1 \alpha$, regulating VEGF expression, with angiogenesis playing a key role in this process. VEGF is an endothelial cell mitogen that promotes the division and migration of vascular endothelial cells and trophoblasts to induce tissue neovascularization. It can also promote the formation of new blood vessels by regulating vascular permeability [29]. Furthermore, VEGF is an important target gene for HIF-1 $\alpha$ because under hypoxic conditions, HIF- $1 \alpha$ not only directly promotes its transcription but also promotes its expression by increasing the stability of VEGF mRNA [26].

Tumor angiogenesis is a tumor vascular model independent of endothelial cells, also known as angiogenic mimicry; that is, tumor cells (not vascular endothelial cells) are arranged on the outer surface of the tube wall, and red blood cells are observed in the lumen. Angiogenic mimicry is a microcirculatory system responsible for tumor growth, together with endothelial-dependent blood vessels and mosaic blood vessels [30]. Therefore, inhibiting angiogenesis is a feasible and reliable treatment method for achieving anticancer effects. Our in vivo and in vitro results confirmed that the effect of treatment with HIF- $1 \alpha$ RNAi combined with ASP was more obvious on HCC angiogenesis than the effects of HIF- $1 \alpha$ RNAi and ASP treatment and that this combined treatment significantly lowered the p-ERK and p-AKT levels but had little influence on the ERK and AKT levels. This indicates that the combination of ASP and HIF- $1 \alpha$ RNAi for the treatment of liver cancer may act by inhibiting angiogenesis through the PI3K and MAPK signaling pathways.

In addition to angiogenesis, HIF- $1 \alpha$ is also involved in the proliferation, apoptosis, invasion, and metastasis of HCC cells. We found that the combination of HIF- $1 \alpha$ RNAi and ASP significantly inhibited the proliferation, invasion, and migration of HCC cells compared with ASP alone and HIF$1 \alpha$ RNAi alone. Previous studies have shown that HIF- $1 \alpha$ promotes cell proliferation by regulating cyclin $\mathrm{A}$ and cyclin $\mathrm{D}$ [31]. The hypoxic microenvironment and new blood vessels provide a "hotbed" and "nourishment," respectively, for HCC metastasis, and cell matrix degradation and epithelial-mesenchymal transition (EMT) lead to poor prognosis of patients with HCC. Moreover, in the process of liver cancer metastasis, HIF- $1 \alpha$ regulates zinc finger transcription factors to affect the expression of EMT markers, such as E-cadherin, N-cadherin, and vimentin, and promotes invasion and metastasis [32]. How HIF- $1 \alpha$ and ASP affect HCC cell metastasis will be the focus of our future research.

RNAi is a powerful tool for suppressing the expression of specific genes and has been widely used in targeted cancer therapies. Activated RNAi can achieve specific and powerful gene silencing, providing more possibilities for the clinical treatment of HCC $[33,34]$. RNAi can regulate cancer cells within cells to improve the efficiency of cancer treatment. These target genes, which are indispensable for tumor maintenance, have few side effects and low risk, can be knocked out or suppressed by RNAi, blocking the inherent immunosuppression and triggering an immune attack on the tumor. Therefore, cancer is one of the main targets for RNAi-based therapy, as it is highly correlated with gene expression and cell proliferation [35]. Experimental studies aimed at silencing HCC-related oncogenes have shown promising prospects. In particular, using RNAi to inhibit the expression of hepatocyte transformation-related genes is an exciting new approach for the treatment of HCC [36]. Moreover, other therapies combined with gene therapy exert stronger anticancer effects than singlegene therapy [37, 38]. In addition to stronger resistance to HCC proliferation, migration, invasion, and angiogenesis, our combination of gene interference technology targeting the key HCC factor HIF- $1 \alpha$ with ASP in the treatment of HCC may have profound implications: (1) ASP can improve the efficiency of gene targeting and increase the transfection rate; (2) ASP can ensure that the RNAi technology is locally and directly released, reducing the incidence of adverse reactions to gene therapy; and (3) combined with ASP, gene therapy can alleviate drug resistance, and its therapeutic effect can be enhanced. Notably, the mechanism by which toxicity and drug resistance are reduced deserves further study.

\section{Conclusions}

Overall, our results indicated that ASP combined with HIF$1 \alpha$ RNAi inhibited HCC cell growth via the PI3K and MAPK signaling pathways. Thus, we suggest that this combination may be an effective method of integrating Western medicine and traditional Chinese medicine for the treatment of liver cancer, which may provide new ideas for the treatment of various malignant tumors such as HCC.

\section{Data Availability}

All data obtained or analyzed during this study are included within the article.

\section{Additional Points}

Reporting Checklist. The authors have completed the ARRIVE reporting checklist. 


\section{Ethical Approval}

Animal care and all animal experiments were approved by the Animal Ethics Committee of the Shanghai Municipal Hospital of Traditional Chinese Medicine, Shanghai University of Traditional Chinese Medicine (SYXK, Shanghai, China 2020-0014), and adhered to local animal care guidelines.

\section{Conflicts of Interest}

All authors declare no conflicts of interest.

\section{Authors' Contributions}

Dongwei Xing and Minguang Zhang conceived and supervised the study; Tingting Zhu and Ziwei Cheng were involved in the acquisition of data. Tingting Zhu and Xiaolin Peng analyzed the data; Tingting Zhu, Ziwei Cheng, and Minguang Zhang wrote the manuscript. All authors have read and approved the final version of the manuscript.

\section{Acknowledgments}

This work was supported by the Natural Science Foundation of Shanghai (Research Grant no. 19ZR1452400) and the National Natural Science Foundation of China (Research Grant no. 81673743).

\section{Supplementary Materials}

The ARRIVE Guidelines Checklist. (Supplementary Materials)

\section{References}

[1] F. Bray, J. Ferlay, I. Soerjomataram, R. L. Siegel, L. A. Torre, and A. Jemal, "Global cancer statistics 2018: GLOBOCAN estimates of incidence and mortality worldwide for 36 cancers in 185 countries," CA: A Cancer Journal for Clinicians, vol. 68, no. 6, pp. 394-424, 2018.

[2] S. K. Asrani, H. Devarbhavi, J. Eaton, and P. S. Kamath, "Burden of liver diseases in the world," Journal of Hepatology, vol. 70, no. 1, pp. 151-171, 2019.

[3] Z. Liu, Y. Jiang, H. Yuan et al., "The trends in incidence of primary liver cancer caused by specific etiologies: results from the global burden of disease study 2016 and implications for liver cancer prevention," Journal of Hepatology, vol. 70, no. 4, pp. 674-683, 2019.

[4] J. D. Yang, P. Hainaut, G. J. Gores, A. Amadou, A. Plymoth, and L. R. Roberts, "A global view of hepatocellular carcinoma: trends, risk, prevention and management," Nature Reviews Gastroenterology \& Hepatology, vol. 16, no. 10, pp. 589-604, 2019.

[5] J. M. Llovet, R. Montal, and A. Villanueva, "Randomized trials and endpoints in advanced HCC: role of PFS as a surrogate of survival," Journal of Hepatology, vol. 70, no. 6, pp. 1262-1277, 2019.

[6] G. L. Semenza, "Targeting HIF-1 for cancer therapy," Nature Reviews Cancer, vol. 3, no. 10, pp. 721-732, 2003.

[7] I. Papandreou, R. A. Cairns, L. Fontana, A. L. Lim, and N. C. Denko, "HIF-1 mediates adaptation to hypoxia by actively downregulating mitochondrial oxygen consumption," Cell Metabolism, vol. 3, no. 3, pp. 187-197, 2006.

[8] C. C.-L. Wong, A. K.-L. Kai, and I. O.-L. Ng, "The impact of hypoxia in hepatocellular carcinoma metastasis," Frontiers of Medicine, vol. 8, no. 1, pp. 33-41, 2014.

[9] X. M. Anguela and K. A. High, "Entering the modern era of gene therapy," Annual Review of Medicine, vol. 70, no. 1, pp. 273-288, 2019.

[10] H. Luo, B. Li, Z. Li, S. J. Cutler, G. O. Rankin, and Y. C. Chen, "Chaetoglobosin $\mathrm{K}$ inhibits tumor angiogenesis through downregulation of vascular epithelial growth factor-binding hypoxia-inducible factor $1 \alpha$," Anti-Cancer Drugs, vol. 24, no. 7, pp. 715-724, 2013.

[11] M. Thakur, P. Connellan, M. A. Deseo et al., "Characterization and in vitro immunomodulatory screening of fructo-oligosaccharides of Asparagus racemosus Willd," International Journal of Biological Macromolecules, vol. 50, no. 1, pp. 77-81, 2012.

[12] R. L. Setten, J. J. Rossi, and S.-P. Han, "The current state and future directions of RNAi-based therapeutics," Nature Reviews Drug Discovery, vol. 18, no. 6, pp. 421-446, 2019.

[13] Z. Tian, G. Liang, K. Cui et al., "Insight into the prospects for RNAi therapy of cancer," Frontiers in Pharmacology, vol. 12, Article ID 644718, 2021.

[14] R. Jian, K. W. Zeng, J. Li, N. Li, Y. Jiang, and P. Tu, “Antineuroinflammatory constituents from Asparagus cochinchinensis," Fitoterapia, vol. 84, pp. 80-84, 2013.

[15] J. Y. Ding, X. Wang, L. L. Weng et al., "Effects of Aspartic polysaccharides on the growth, invasion and migration of HCC cells under hypoxic conditions," Shandong Medical Journal, vol. 14, pp. 23-26, 2017, [in Chinese].

[16] W. Cheng, Z. Cheng, D. Xing, and M. Zhang, “Asparagus polysaccharide suppresses the migration, invasion, and angiogenesis of hepatocellular carcinoma cells partly by targeting the HIF-1/VEGF signalling pathway in vitro," Evidence Based Complementary Alternative Medicine, vol. 2019, Article ID 3769879, 10 pages, 2019.

[17] E. H. Barriga, P. H. Maxwell, A. E. Reyes, and R. Mayor, "The hypoxia factor Hif- $1 \alpha$ controls neural crest chemotaxis and epithelial to mesenchymal transition," Journal of Cell Biology, vol. 201, no. 5, pp. 759-776, 2013.

[18] F. Agani and B.-H. Jiang, "Oxygen-independent regulation of HIF-1: novel involvement of PI3K/AKT/mTOR pathway in cancer," Current Cancer Drug Targets, vol. 13, no. 3, pp. 245-251, 2013.

[19] M. Müller, T. G. Bird, and J. C. Nault, "The landscape of gene mutations in cirrhosis and hepatocellular carcinoma," Journal of Hepatology, vol. 72, pp. 990-1002, 2020.

[20] A. J. Craig, J. von Felden, T. Garcia-Lezana, S. Sarcognato, and A. Villanueva, "Tumour evolution in hepatocellular carcinoma," Nature Reviews Gastroenterology \& Hepatology, vol. 17, no. 3, pp. 139-152, 2020.

[21] H. S. Luo and D. H. Zhou, Antitumor Chinese Herbs in Common Use, Guangdong Science and Technology Press, Dongguan, China, 1981.

[22] B. Nath and G. Szabo, "Hypoxia and hypoxia inducible factors: diverse roles in liver diseases," Hepatology, vol. 55, no. 2, pp. 622-633, 2012.

[23] P. Lee, N. S. Chandel, and M. C. Simon, "Cellular adaptation to hypoxia through hypoxia inducible factors and beyond," Nature Reviews Molecular Cell Biology, vol. 21, no. 5, pp. 268-283, 2020.

[24] N. M. Phuong, S. Lee, and Y. M. Lee, "Epigenetic regulation of hypoxia inducible factor in diseases and therapeutics," Archives of Pharmacal Research, vol. 36, pp. 252-263, 2013. 
[25] A. F. McGettrick and L. A. J. O'Neill, "The role of HIF in immunity and inflammation," Cell Metabolism, vol. 32, no. 4, pp. 524-536, 2020.

[26] R. S. Apte, D. S. Chen, and N. Ferrara, "VEGF in signaling and disease: beyond discovery and development," Cell, vol. 176, no. 6, pp. 1248-1264, 2019.

[27] B. Keith, R. S. Johnson, and M. C. Simon, "HIF1 $\alpha$ and HIF2 $\alpha$ : sibling rivalry in hypoxic tumour growth and progression," Nature Reviews Cancer, vol. 12, no. 1, pp. 9-22, 2011.

[28] X.-M. Yang, Y.-S. Wang, J. Zhang et al., "Role of PI3K/akt and MEK/ERK in mediating hypoxia-induced expression of HIF$1 \alpha$ and VEGF in laser-induced rat choroidal neovascularization," Investigative Ophthalmology \& Visual Science, vol. 50, no. 4, pp. 1873-1879, 2009.

[29] M. Simons, E. Gordon, and L. Claesson-Welsh, "Mechanisms and regulation of endothelial VEGF receptor signalling," Nature Reviews Molecular Cell Biology, vol. 17, no. 10, pp. 611-625, 2016.

[30] Q. Luo, J. Wang, W. Zhao et al., "Vasculogenic mimicry in carcinogenesis and clinical applications," Journal of Hematology \& Oncology, vol. 13, no. 1, p. 19, 2020.

[31] Z. Q. Xu, E. Liu, C. Peng et al., "Role of hypoxia-inducible- $1 \alpha$ in hepatocellular carcinoma cells using a tet-on inducible system to regulate its expression in vitro," Oncology Reports, vol. 27, pp. 573-578, 2012.

[32] L. Zhang, G. Huang, X. Li et al., "Hypoxia induces epithelialmesenchymal transition via activation of SNAI1 by hypoxiainducible factor- $1 \alpha$ in hepatocellular carcinoma," $B M C$ Cancer, vol. 13, no. 1, p. 108, 2013.

[33] B. Hu, L. Zhong, Y. Weng et al., "Therapeutic siRNA: state of the art," Signal Transduction and Targeted Therapy, vol. 5, no. 1, p. 101, 2020.

[34] Y. Dong, D. J. Siegwart, and D. G. Anderson, "Strategies, design, and chemistry in siRNA delivery systems," Advanced Drug Delivery Reviews, vol. 144, pp. 133-147, 2019.

[35] B. Mansoori, S. S. Sandoghchian, and B. Baradaran, "RNA interference and its role in cancer therapy," Advanced Pharmaceutical Bulletin, vol. 4, pp. 313-321, 2014.

[36] P. Arbuthnot and L. J. Thompson, "Harnessing the RNA interference pathway to advance treatment and prevention of hepatocellular carcinoma," World Journal of Gastroenterology, vol. 14, no. 11, pp. 1670-1681, 2008.

[37] F. Perri, F. Longo, M. Giuliano et al., "Epigenetic control of gene expression: potential implications for cancer treatment," Critical Reviews in Oncology/Hematology, vol. 111, pp. 166172, 2017.

[38] M. Sopo, M. Anttila, H. Sallinen et al., "Antiangiogenic gene therapy with soluble VEGF-receptors $-1,-2$ and -3 together with paclitaxel prolongs survival of mice with human ovarian carcinoma," International Journal of Cancer, vol. 131, no. 10, pp. 2394-2401, 2012. 